\title{
Nanoscaled $\mathrm{TiO}_{2} /$ Ag Catalysts and Their Photodecomposition Characteristics
}

\author{
Shih-Chin Lin and Cheng-Hsiung Peng, ${ }^{1, *}$ \\ Materials Research Laboratories, Industrial Technology Research Institute, \\ Chung Li 32023, Taiwan, R.O.C. \\ ${ }^{1}$ Department of Chemical Engineering and Materials Science, \\ Ming Hsin University of Science and Technology, Hsinfeng, Hsinchu 30401, Taiwan, R.O.C.
}

(Received July 17, 2008; accepted November 17, 2008)

Key words: photocatalytic, photodecomposition, dendrite, methylene blue

The concentration of $\mathrm{AgNO}_{3}$ plays a significant role in the formation and growth of silver nanoparticles in the preparation of catalysts. When the concentration of $\mathrm{AgNO}_{3}$ was decreased to $0.2 \mathrm{wt} \%$, flakelike $\mathrm{Ag}$ was observed. The corresponding zeta potentials of the $\mathrm{TiO}_{2}$ solution at pHs of $11,6.2$, and 3 suggest that the electric repulsion between the $\mathrm{TiO}_{2}$ nanoparticles was very strong in both alkaline and acidic solutions, causing their "effective dispersion." Therefore, a highly dispersed nanostructured $\mathrm{TiO}_{2} / \mathrm{Ag}$ catalyst can be synthesized at a $\mathrm{pH}$ of 11 in alkaline solution. Nearly all the dimethyblue target pollutant present at high concentrations was removed when the photoreaction was performed over a short period of time. This novel nano- $\mathrm{TiO}_{2}$ photocatalyst exhibits excellent photocatalytic activity because it is well-dispersed. In addition, no dispersant or organic binder was used for this synthetic process.

\section{Introduction}

Environmental purification using $\mathrm{TiO}_{2}$-type photocatalysts has attracted much attention owing to the increasing number of recent environmental problems in society. The photodecomposition of various pollutants by $\mathrm{TiO}_{2}$ has been demonstrated to be efficient under ultraviolet light. ${ }^{(1-7)}$ The photocatalytic activity of $\mathrm{TiO}_{2}$ can also be enhanced by modifying the $\mathrm{TiO}_{2}$ surface with noble metals and metal oxides. ${ }^{(8)}$ These photocatalysts are utilized in many approaches. Recently, $\mathrm{TiO}_{2}$ photocatalysts anchored on supporting materials with large surface areas have been developed to eliminate the shortcomings of the filtration and the suspension of fine photocatalyst particles. ${ }^{(5)}$ In addition, $\mathrm{TiO}_{2}$ photocatalysts anchored on various substrates can be prepared using a pasting treatment, an ionized cluster beam (ICB) method or a sol-gel method. ${ }^{(6)}$ The solgel method is frequently adopted to prepare $\mathrm{TiO}_{2}$ thin films on supported substrates. . $^{(7,10,13)}$ However, heat treatment may cause the phase transition of $\mathrm{TiO}_{2}$ and reduce the photocatalytic activity. ${ }^{(5)}$

${ }^{*}$ Corresponding author: e-mail: chpeng@must.edu.tw 
In this study, a process for the anchoring of well-dispersed nano- $\mathrm{TiO}_{2}$ on a metal carrier using a binder-free, low-temperature process was investigated. Well-dispersed nano- $\mathrm{TiO}_{2}$ deposited on a branchlike silver (Ag) carrier, called a "nano- $\mathrm{TiO}_{2} / \mathrm{Ag}$ catalyst," was synthesized to overcome the aforementioned shortcomings. The preparation, morphology and reaction kinetics of the photocatalytic activity of the nano- $\mathrm{TiO}_{2} / \mathrm{Ag}$ catalyst will also be discussed.

\section{Experimental}

A Ag carrier was prepared on the basis of the reaction, $2 \mathrm{Ag}^{+}+\mathrm{Cu} \rightarrow 2 \mathrm{Ag}+\mathrm{Cu}^{2+}$. The net redox potential of the reaction is $0.5 \mathrm{~V}$, indicating that the reaction occurs spontaneously. In a pretest, the formation of the branchlike Ag carrier was favored in acidic solution at high concentrations. ${ }^{(14)}$ Bulk copper $(\mathrm{Cu})$ was placed in $\mathrm{AgNO}_{3}$ solution at a ratio of 0.2-1.5: 100 (wt\%) $\mathrm{AgNO}_{3}$ :water to yield $\mathrm{Ag}$ particles. Nitric acid was added to adjust the $\mathrm{pH}$ of the solution to 3 . The solution temperature was set to $25^{\circ} \mathrm{C}$ and maintained for $2 \mathrm{~h}$. The precipitate was rinsed with DI water to remove any residues.

Secondly, an appropriate amount of $\mathrm{TiO}_{2}$ particles (P25, Degussa) was placed in solutions at various $\mathrm{pH}$ values, obtained by adjusting the amount of $\mathrm{NH}_{3(\mathrm{aq})}$ or nitric acid added. The solutions were treated ultrasonically for $90 \mathrm{~min}$. No dispersing agent was added to the solutions. The experimental design was such that $5 \mathrm{wt} \% \mathrm{TiO}_{2}$ was mixed with the Ag carrier under various $\mathrm{pH}$ conditions. A critical coverage ratio of approximately $5 \% \mathrm{TiO}_{2}$ was identified: exceeding this dosage of $\mathrm{TiO}_{2}$ may result in aggregation under all test $\mathrm{pH}$ conditions. The mixture was stirred for $30 \mathrm{~min}$ to increase the number of opportunities for contact between the nano- $\mathrm{TiO}_{2}$ particles and the $\mathrm{Ag}$ carriers. Finally, a composite of the nano- $\mathrm{TiO}_{2}$ particles and $\mathrm{Ag}$ carrier was synthesized by washing, filtering and drying, in that order. Table 1 shows the characteristics of the nano- $\mathrm{TiO}_{2} / \mathrm{Ag}$ catalysts used in this study.

Methylene blue (MB) is a representative dye that is commonly adopted to evaluate the catalytic activity of a catalyst. The test conditions were as follows: $1 \mathrm{~g}$ of catalyst, $30 \mathrm{ml}$ of $100 \mathrm{ppm}$ MB solution, UV light with a wavelength of $254 \mathrm{~nm}$, and an illumination intensity of $4 \mathrm{~mW} / \mathrm{cm}^{2}$. The UV lamp was placed $6 \mathrm{~cm}$ above the test sample. The mixture (MB and catalyst) was stirred gently while being irradiated. A centrifuge was used to separate the mixture after irradiation had been completed. The

Table 1

Characteristics of the nano- $\mathrm{TiO}_{2} / \mathrm{Ag}$ catalysts used in this study.

\begin{tabular}{ccc}
\hline Catalyst name & $\mathrm{TiO}_{2}$ nanoparticle content (wt\%) & $\mathrm{TiO}_{2}$ phase \\
\hline Cat. $_{\mathrm{pH} 11}$ & 4.7 & $80 \%$ anatase \\
Cat. ${ }_{\mathrm{pH} 6.2}$ & 4.8 & $80 \%$ anatase $^{* *}$ \\
Cat. ${ }_{\mathrm{pH} 3}$ & $0.2^{*}$ & $80 \%$ anatase \\
\hline
\end{tabular}

*The $\mathrm{TiO}_{2}$ nanoparticle content of Cat. ${ }_{\mathrm{pH}} 3$ was synthesized at $\mathrm{pH} 3$; the positive $\mathrm{TiO}_{2}$ was difficult to adhere to the surface of positive Ag carrier.

** The $\mathrm{TiO}_{2}$ nanoparticles were purchased from Ultra Fine Chemical Technology Corporation (Degussa P-25). 
absorption of the MB supernatant was then determined using a spectrophotometer (Unico UV2102). A blank experiment (without a catalyst) was also performed; the results indicated that irradiation did not significantly change the MB absorbance. The photocatalytic activity was defined as

$$
\eta=\frac{C_{\text {initial }}-C_{\text {irradiation }}}{C_{\text {initial }}} \times 100 \%,
$$

where $C_{\text {initial }}$ and $C_{\text {irradiation }}$ are the absorbance of MB before and after irradiation. The crystal phase and morphology of the catalysts were observed by X-ray diffraction, transmission electron microscopy (TEM) and field emission scanning electron microscopy (FE-SEM).

\section{Results and Discussion}

The SEM images of the Ag nanoparticles are shown in Fig. 1. This figure shows the typical SEM images of the product obtained by self-reducing solutions with $\mathrm{AgNO}_{3}$ concentrations from 0.1 to $1.5 \mathrm{wt} \%$. It is apparent that the Ag nanoparticles display

(a)

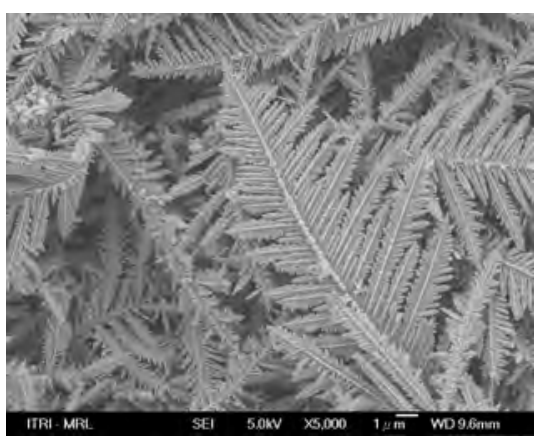

(c)

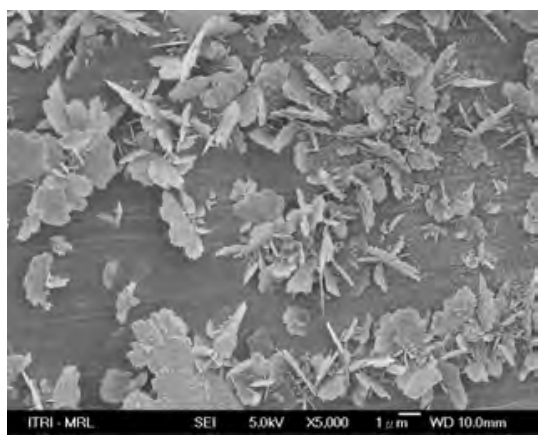

(b)

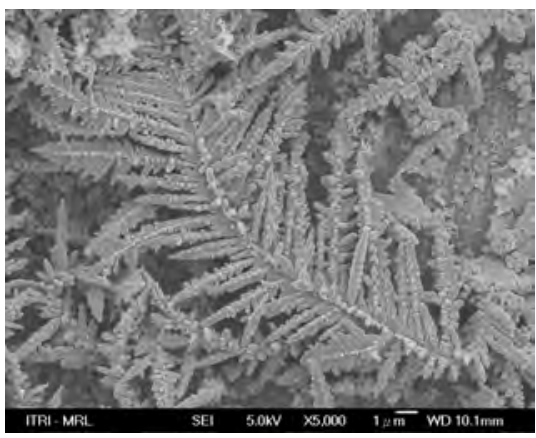

(d)

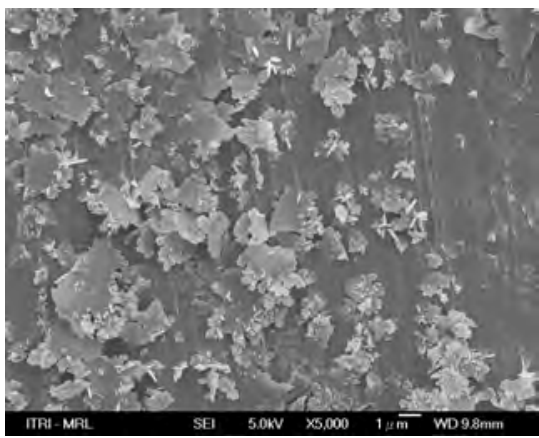

Fig. 1. SEM images of Ag nanoparticles developed from $\mathrm{AgNO}_{3}$ concentrations of (a) 1.5, (b) 1.0, (c) 0.5 , and (d) $0.2 \mathrm{wt} \%$. 
dendritic growth at concentrations larger than $0.5 \mathrm{wt} \% \mathrm{AgNO}_{3}$. The excess of silver in the solution may be favorable for aggregation and growth into the dendritic structures of the Ag cluster. It was found that the concentration of $\mathrm{AgNO}_{3}$ plays a significant role in the formation and growth of the silver nanoparticles. When the concentration of $\mathrm{AgNO}_{3}$ is decreased to $0.2 \mathrm{wt} \%$, flakelike $\mathrm{Ag}$ nanoparticles of $1 \mu \mathrm{m}$ diameter are observed, as shown in Figs. 1(c) and 1(d).

This indicates that the concentration of $\mathrm{AgNO}_{3}$ also plays a key role in the formation of Ag nanoparticles. In principle, crystal growth and crystal morphology are governed by the degree of supersaturation, the diffusion of the reaction species to the surface of the crystals, and the structural anisotropy of the crystals. The dendritic growth is usually expected in the diffusion-limited regime, away from equilibrium conditions. Therefore, an increasing $\mathrm{AgNO}_{3}$ concentration could probably change the reaction from an equilibrium to a nonequilibrium process and lead to the morphology change from flake to dendrite. Under such conditions and high ion concentrations, crystal growth will be anisotropic and nonlinear to promote the growth of dendrite structures along a specific direction.

Figure 2 shows the XRD patterns of the as-prepared $1.5 \mathrm{wt} \% \mathrm{AgNO}_{3}$ sample, in

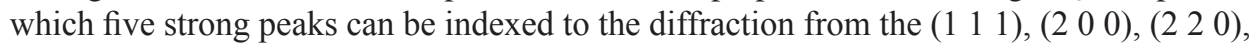
(3 1 1), and (2 22 ) of the face-centered cubic (fcc) Ag, and no impurity peaks from silver oxide were detected.

Figure 3(a) shows the SEM images of well-defined silver dendrites with at least three axial and branchlike shapes. It was found that the side branches are symmetric and that their angles to the main branches are all about $60^{\circ}$, which implies that all side branches grow along the same direction. From bright-field and dark-field TEM images (Figs. 3(b) and 3(c)), the side branches of these dendritic Ag are constructed following the growth of self-assembled well-crystallized Ag nanocrystals with diameters of 50-60 nm and lengths up to $200 \mathrm{~nm}$. The inset SAED pattern from one of the left-side branches in Fig. 3(d) reveals that the Ag dendrite displays almost the same growth direction with very few variations between the first axial and other axial positions and the side branch direction assembles along the $\left[\begin{array}{lll}0 & 1 & 1\end{array}\right]$ direction. This may suggest that the large dendrites grow

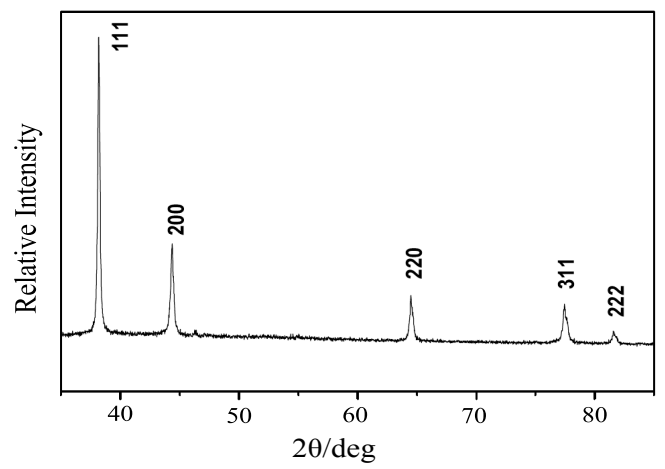

Fig. 2. XRD patterns of the as-prepared $1.5 \mathrm{wt} \% \mathrm{AgNO}_{3}$ sample. 


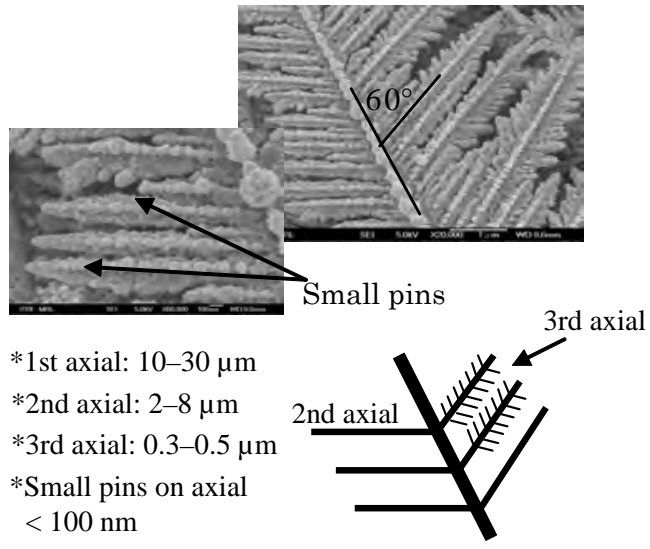

1st axial

(a)

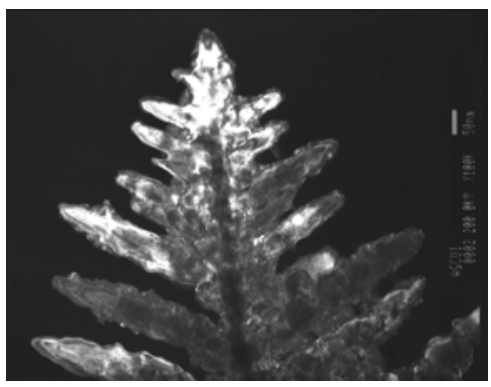

(c)

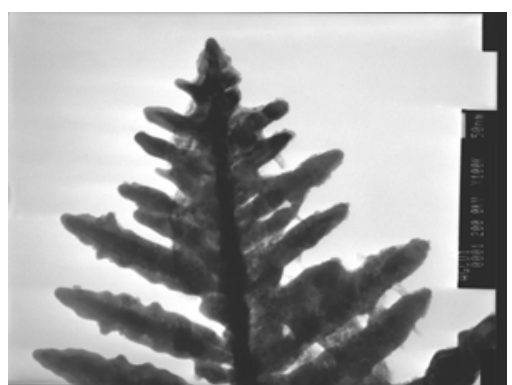

(b)

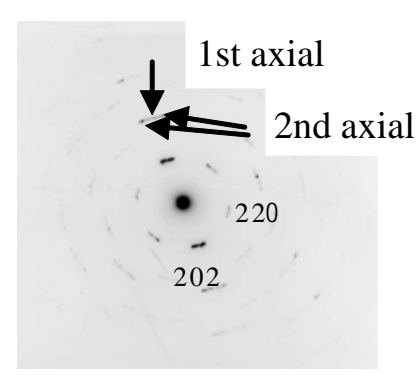

(d)

Fig. 3. Images of well-defined silver dendrites with branchlike shapes: (a) SEM image, (b) brightfield TEM image, (c) dark-field TEM image, (d) selected-area diffraction pattern.

from small clusters and that in many places the dendrites lack corners and arms.

In the catalyst preparation, $\mathrm{TiO}_{2}$ nanoparticles were initially suspended in solution. The corresponding zeta potentials of the $\mathrm{TiO}_{2}$ solution at pHs 11,6.2, and 3 were found to be $-55,-2.5$, and $28 \mathrm{mV}$, respectively. These results revealed that the $\mathrm{TiO}_{2}$ particles tended to be negatively charged by the excess bonding of the hydroxyl ion $\left(\mathrm{OH}^{-}\right)$in alkaline solution ( $\mathrm{pH} 11$ ), and positively charged by the excess bonding of the hydrogen ion $\left(\mathrm{H}_{3} \mathrm{O}^{+}\right)$in acidic solution $(\mathrm{pH} 3)$, suggesting that the electric repulsion between the $\mathrm{TiO}_{2}$ nanoparticles was very strong in both alkaline and acidic solutions, causing their "effective dispersion".

The mixing of Ag particles with the $\mathrm{TiO}_{2}$ particle solution at pHs 11, 6.2, and 3, resulted in the composite shown in Figs. 4(a)-4(c), respectively. A composite of welldispersed nano- $\mathrm{TiO}_{2}$ anchored on the Ag carrier was formed in alkaline solution ( $\mathrm{pH} 11$, Fig. 4(a)), while nano- $\mathrm{TiO}_{2}$ aggregated in neutral solution (pH 6.2, Fig. 4(b). Almost no $\mathrm{TiO}_{2}$ particles were deposited on the Ag carrier in acidic solution (pH 3, Fig. 4(c)). The 


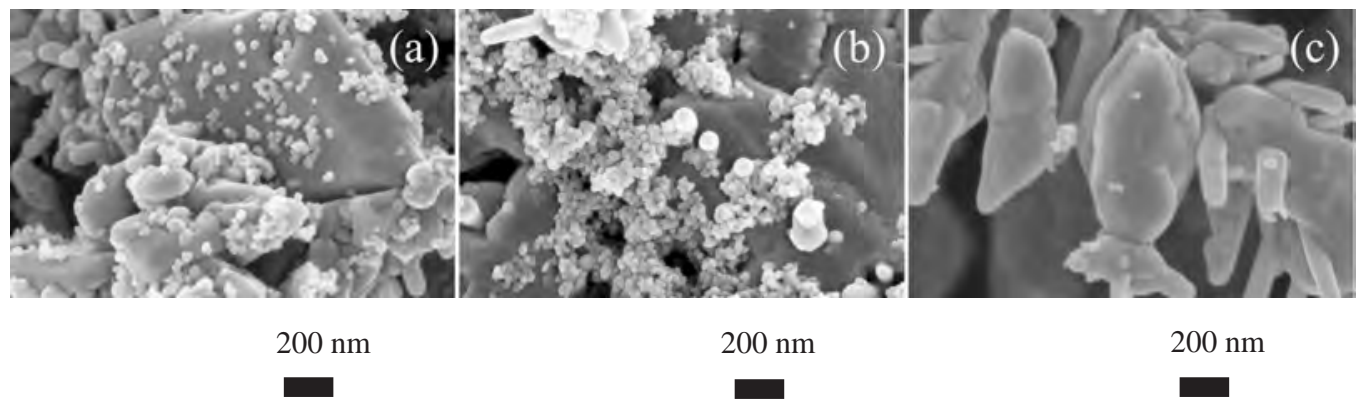

Fig. 4. Effect of $\mathrm{pH}$ on the morphology of the nano- $\mathrm{TiO}_{2} / \mathrm{Ag}$ photocatalyst. (a) $\mathrm{pH}$ 11, (b) $\mathrm{pH}$ 6.2. (c) $\mathrm{pH} 3$.

results indicated that the $\mathrm{pH}$ significantly affects the combination of nano- $\mathrm{TiO}_{2}$ and $\mathrm{Ag}$ carriers. The surface of the Ag carrier is preferentially oxidized because of its extreme activity, if the size of the $\mathrm{Ag}$ particles is reduced to nanoscale. ${ }^{(14)}$ Accordingly, the positively oxidized $\mathrm{Ag}$ surface spontaneously attracts negative $\mathrm{TiO}_{2}$ particles in alkaline solution, yielding the composite, "well-dispersed" $\mathrm{TiO}_{2}$ anchored on Ag carriers, as shown in Fig. 4(a). In neutral solution ( $\mathrm{pH}=6.2$ ), the repulsive force between the nano$\mathrm{TiO}_{2}$ particles is very weak, because neutral pH is very close to the isoelectric point. ${ }^{(15)}$ $\mathrm{H}_{2} \mathrm{O}$ molecules provide a "bridge" between the nano- $\mathrm{TiO}_{2}$ particles via hydrogen bonding, resulting in the aggregation of $\mathrm{TiO}_{2}$ particles, as shown in Fig. 4(b). Positive $\mathrm{TiO}_{2}$ particles could not be easily anchored on the positive Ag carrier, because of the electric repulsion, as shown in Fig. 4(c). Consequently, the effective dispersion of the nano- $\mathrm{TiO}_{2}$ and $\mathrm{Ag}$ carriers is governed by electrostatic attraction, achieved by adjusting the $\mathrm{pH}$ of solution.

The catalysts prepared at various pHs were then examined to determine the photocatalytic activity. As shown in Fig. 5, gradual changes in the absorbance of MB were observed from its characteristic absorptions at 250, 290, and $666 \mathrm{~nm}$. The absorbance decreased in the order Cat. ${ }_{{ }_{\mathrm{pH}}{ }_{11}}$, Cat. ${ }_{{ }_{\mathrm{pH}} 6.2}$, and Cat. ${ }_{{ }_{\mathrm{pH}} 3}$ with an irradiation period of $20 \mathrm{~min}$. This result indicates that the " $\mathrm{pH}$ status in the catalyst preparation" not only affects the dispersion between the nano- $\mathrm{TiO}_{2}$ particles but also significantly affects their photocatalytic activity, as can be clearly distinguished from the results in Figs. 4 and 5. The Cat. ${ }_{\mathrm{pH}} 6.2$ has a higher MB absorbance (and thus a lower photocatalytic activity) than $\mathrm{Cat}_{{ }_{\mathrm{pH}}{ }_{11}}$, even though both nano- $\mathrm{TiO}_{2}$ particle loadings are identical. The photocatalytic activity was evidently reduced by the aggregation of nano- $\mathrm{TiO}_{2}$ particles. Larger aggregated nano- $\mathrm{TiO}_{2}$ particles correspond to less surface area exposed to UV irradiation.

Therefore, the enhancement of the photocatalytic activity of the nano- $\mathrm{TiO}_{2} / \mathrm{Ag}$ catalyst depends on effective dispersion and an appropriate proportion of nano- $\mathrm{TiO}_{2}$, which can be achieved in this approach without adding a dispersive agent or binder.

Figure 6 plots photocatalytic activity as a function of reaction time. The photocatalytic activity also followed the order of Cat. ${ }_{\mathrm{pH}}{ }_{11}$, Cat. ${ }_{\mathrm{pH}} 6_{2.2}$, and $\mathrm{Cat}_{{ }_{\mathrm{pH}} 3}$ for various time periods of irradiation. Cat. $_{{ }_{\mathrm{pH}}{ }_{11}}$ and Cat. ${ }_{\mathrm{pH}} 6.2$ reached a decomposition efficiency of over $90 \%$ after an irradiation time of $2 \mathrm{~h}$. Cat. ${ }_{\mathrm{pH}} 11$ was associated with 


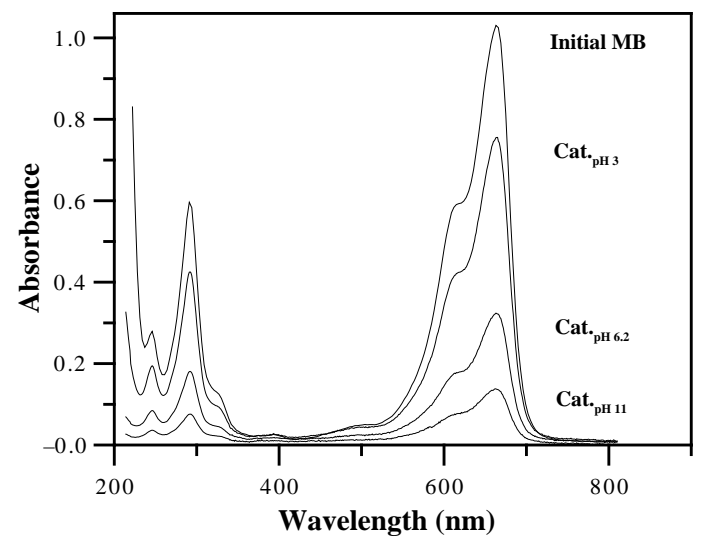

Fig. 5. MB absorbance of the nano- $\mathrm{TiO}_{2} / \mathrm{Ag}$ catalysts used in this study. The data was obtained after an irradiation of $20 \mathrm{~min}$.

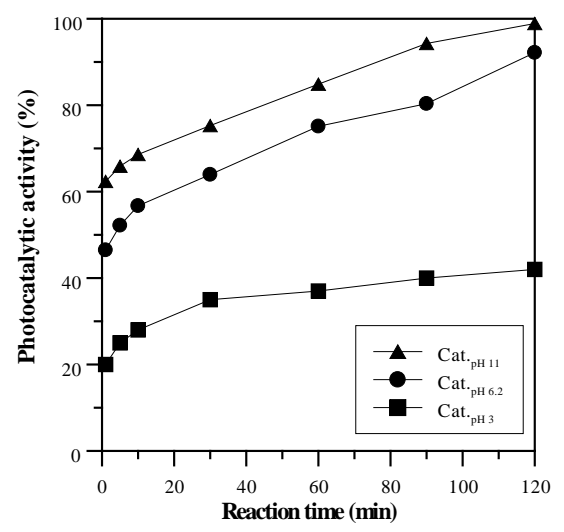

Fig. 6. Photocatalytic activity of the catalysts as a function of the irradiation time. Experimental conditions: $1 \mathrm{~g}$ of catalyst, $30 \mathrm{ml}$ of $100 \mathrm{ppm} \mathrm{MB}$ solution.

the near complete decomposition of MB after irradiation for $1 \mathrm{~h}$. Notably, the MB concentration $(100 \mathrm{ppm})$ tested herein is much higher than the $10 \mathrm{ppm}$ tested in the literature $[3,5,10]$. A high initial $\mathrm{MB}$ concentration was removed completely in a short period, indicating that the well-dispersed nano- $\mathrm{TiO}_{2} / \mathrm{Ag}$ catalyst exhibited outstanding catalytic activity. Cat. ${ }_{\mathrm{pH}} 3$ comprised mainly the Ag carrier, which still had a decomposition efficiency of $40 \%$ after irradiation for $2 \mathrm{~h}$, suggesting that the Ag carrier also exhibited a high photocatalytic activity.

The reaction constants $(\mathrm{k})$ calculated from Fig. 6 were 0.0269, 0.0142, and 0.0024 for Cat. ${ }_{\mathrm{pH}} 11$, Cat. ${ }_{\mathrm{pH}} 6.2$, and $\mathrm{Cat}_{{ }_{\mathrm{pH}} 3}$, respectively. The rate constants of all nano- $\mathrm{TiO}_{2} / \mathrm{Ag}$ catalysts were determined for a first-order reaction, and were consistent with the results found in Refs. 3, 5, and 10. However, it was found that the reaction rate constant of Cat. ${ }_{\mathrm{pH}} 11$ obtained herein clearly exceeded those in Refs. 3, 5, and 10. Zainal et al.(5) reported that a 
$\mathrm{TiO}_{2}$ thin film was prepared using a typical sol-gel method and then treated at $600^{\circ} \mathrm{C}$ for 6 h. The $\mathrm{TiO}_{2}$ /glass contained a rutile-phase $\mathrm{TiO}_{2}$. Unfortunately, the calcination period was usually several hours to ensure strong adhesion on the substrate. The amount and crystallinity of the formed rutile increased with the calcination temperature. In this study, well-dispersed nano- $\mathrm{TiO}_{2}$ particles were combined with Ag carriers in alkaline solution. No further thermal annealing was applied in the catalyst preparation. The aggregation or phase transition of the $\mathrm{TiO}_{2}$ particles did not occur in the catalyst preparation discussed herein. Therefore, the photocatalytic activity was enhanced by the increase in the effective reactive surface area of the "well-dispersed" nano- $\mathrm{TiO}_{2}$ particles.

\section{Summary}

A highly dispersed nano- $\mathrm{TiO}_{2} / \mathrm{Ag}$ catalyst was synthesized in alkaline solution. Nearly all of the dimethyl-blue target pollutant present at high concentrations was removed when the photoreaction was performed over a short period of time. This novel nano- $\mathrm{TiO}_{2}$ photocatalyst exhibits excellent photocatalytic activity because it is welldispersed. Since no dispersant or organic binder was used, this synthetic process has the advantages of low cost and convenience.

\section{Acknowledgement}

This work was financially supported by the National Science Council of the Republic of China, Taiwan under Contract NSC96-2218-E-159-001.

\section{References}

1 C. H. Kwon, H. Shin, J. H. Kim, W. S. Choi and K. H. Yoon: Mater. Chem. Phys. 86 (2004) 78.

2 M. Inagaki, T. Imai, T. Yoshikawa and B. Tryba: Appl. Catal., B 51 (2004) 247.

3 S. Senthilkumaar, K. Porkodi and R. Vidyalakshmi: J. Photochem. Photobiol., A 170 (2005) 225.

4 P. Fu, Y. Luan and X. Dai: J. Mol. Catal., A 221 (2004) 81.

5 Z. Zainal, L. K. Hui, M. Z. Hussein, Y. H. Taufiq-Yap, A. H. Abdullah and I. Ramli: J. Hazard. Mater., B 125 (2005) 113.

6 S.-Y. Lu, C.-H. Chang, C.-H. Yu, H.-L. Chen and Y.-H. Lo: J. Mater. Res. 20 (2005) 1523.

7 X.-Y. Chuan, M. Hirano and M. Inagaki: Appl. Catal., B 51 (2004) 255.

8 M. I. Litter: Appl. Catal., B 23 (1999) 89.

9 L. Zhang, J. C. Yu, H. Y. Yip, Q. Li, K. W. Kwong, A.-W. Xu and P. K. Wong: Langmuir 19 (2003) 10372.

10 S. Senthilkumaar, K. Porkodi, R. Gomathi, A. G. Maheswari and N. Manonmani: Dyes Pigments 69 (2006) 22.

11 C. He, Y. Yu, X. Hu and A. Larbot: Appl. Surf. Sci. 200 (2002) 239.

12 X. You, F. Chen, J. Zhang and M. Anpo: Catal. Lett. 102 (2005) 247.

13 J. Yu, J. Xiong, B. Cheng and S. Liu: Appl. Catal., B 60 (2005) 211.

14 C.-H. Wu, C.-L. Chang, C. Y. Kuo: React. Kinet. Catal. Lett. 86 (2005) 37.

15 Y. H. Cheng and S. Y. Cheng: Nanotechnology 15 (2004) 171.

16 Y. Zhao, Y. Zhang, W. Xing and N. Xu: Desalination 177 (2005) 59. 